\title{
LAS SECUELAS DE LOS TÓPICOS FOLCLÓRICOS DEL CINE ESPAÑOL. UN DIAGNÓSTICO DE LOS FORMATOS DE ENTRETENIMIENTO TELEVISIVOS ${ }^{1}$
}

\author{
María Jesús Ruiz Muñoz \\ (Universidad de Málaga) \\ mariajesus@uma.es
}

\begin{abstract}
Resumen: La imagen estereotipada de Andalucía estuvo inicialmente marcada por la influencia de diferentes vehículos culturales como la novela, los carteles y el teatro. Los clichés relacionados con lo andaluz fueron posteriormente adoptados por el cine español, especialmente a partir de los años treinta, y se impusieron con fuerza durante el periodo franquista. A partir de los setenta, estas fórmulas comenzaron a perder su hegemonía en la gran pantalla. Sin embargo, continuaron claramente vigentes a través de los formatos de entretenimiento televisivos, en los que han permanecido notablemente arraigadas hasta la actualidad.
\end{abstract}

Palabras clave: Andalucía, estereotipo, tópico, televisión, cine.

Abstract: Initially, the stereotyped image of Andalusia was profoundly influenced by cultural vehicles like novel, posters and theatre. The stereotypes related to Andalusian culture were subsequently adopted by the Spanish Cinema, especially starting from the Thirties, and were strongly imposed during Franco regime. Starting from the Seventies, these formules began to lose their significance in the Cinema. Nevertheless, these formules continued certainly in force through the entertainment television formats, where they have been clearly remained in untill present time.

Keywords: Andalusia, stereotype, topic, television, cinema.

\section{INTRODUCCIÓN}

I proceso de construcción y difusión de la imagen estereotipada de Andalucía que ha llegado hasta nuestros días ha estado significativamente marcado, desde sus orígenes, por la influencia de diferentes vehículos culturales. Recordemos, en este sentido, la producción literaria de los viajeros románticos europeos que recorrieron España en el siglo XIX y, posteriormente, la novela costumbrista, los carteles y el teatro. Esta persistencia en la representación tópica de Andalucía y de lo andaluz fue el factor que facilitó que la misma imagen se adoptara en las películas españolas ya desde los inicios del cine.

${ }^{1} \mathrm{El}$ presente trabajo constituye un resultado del proyecto "Personajes, acciones y escenarios andaluces en el cine español (1934-2006)", financiado por el Centro de Estudios Andaluces (Junta de Andalucía). 
Las secuelas de los tópicos folclóricos del cine español. Un diagnóstico de los formatos de entretenimiento televisivos

En torno a la década de los treinta, el cine español contribuyó de manera decisiva en la transmisión de la imagen de una Andalucía atrasada con respecto al resto del país y caracterizada por una forma de vida que se guiaba por una pasión irracional. No obstante, fue durante el periodo franquista cuando se consolidaron férreamente los clichés relacionados con esta región, hasta el punto que la especificidad de lo andaluz llegó a asociarse al cine que exaltaba la españolidad con fines propagandísticos ${ }^{2}$. De este modo, quedó gravemente distorsionada la percepción de la realidad andaluza que se tenía en el exterior e incluso la imagen que los propios andaluces tenían de sí mismos.

A partir de los años sesenta, coincidiendo con la apertura del régimen franquista y con la mayor diversidad en todos los ámbitos de la producción cinematográfica, se produjeron cambios paulatinos en la representación de Andalucía. Los rasgos dialectales de las clases populares, los números folclóricos y los escenarios idílicos andaluces resultaban cada vez menos acordes con la imagen de modernidad que se pretendía transmitir. Pese a los esfuerzos por intentar mantener el género folclórico, la fórmula se fue agotando inevitablemente.

Asimismo, la etapa de Transición democrática, en la que se produjeron transformaciones de todo orden en la vida política y social, constituyó un punto de inflexión para la aparición de discursos endógenos sobre Andalucía que estuvieron marcados por un carácter más reflexivo y por una construcción más matizada de los personajes y de los espacios representados ${ }^{3}$.

Varias décadas después, podemos afirmar que los títulos folclóricos de ambientación andaluza han perdido definitivamente su hegemonía en el cine español, a pesar de que hasta hoy podamos encontrar esporádicamente algunos ejemplos ${ }^{4}$. Sin embargo, los tópicos asociados a la Andalucía idílica que inundó la gran pantalla han arraigado firmemente en el medio televisivo. $Y$ no sólo nos referimos al éxito que tienen las reposiciones de clásicos nacionales en espacios como "Cine de barrio" (TVE-1, 1995- ).

Manuel Palacio (2002: 3-4) plantea una interesante reflexión sobre el papel de las series andaluzas durante la Transición democrática:

¿Será casualidad que las dos series emblemáticas ["Curro Jiménez" y "Verano azul"] se desarrollen en Andalucía y el que sus dos personajes principales, Curro y Chanquete,

\footnotetext{
${ }^{2} U n$ análisis pormenorizado de los mecanismos que rigieron este proceso puede encontrarse en SÁNCHEZ ALARCÓN et al (2002).

${ }^{3}$ Acerca de esta etapa del cine andaluz, consúltese TRENZADO ROMERO (2000) y RUIZ MUÑOZ (2008).

${ }^{4}$ Entre estas excepciones destacamos "Yo soy ésa" (Luis Sanz, 1990) por tratarse de la más ajustada a los esquemas del cine folclórico de antaño. De todos modos, durante las últimas décadas, la mayor parte de las películas españolas que se han nutrido explícitamente de este género lo han hecho con una intencionalidad crítica: "Las cosas del querer" (Jaime Chavarri, 1989), "La Lola se va a los puertos" (Josefina Molina, 1993), "Las cosas del querer II" (Jaime Chavarri, 1995), "La niña de tus ojos" (Fernando Trueba, 1998).
} 
sean de esa comunidad? A lo mejor lo que ocurre es que en la batalla de las imágenes, decisiva para la consolidación democrática, las necesarias operaciones realizadas de construcción de un imaginario nacional democrático, modélicamente representado por la figura de Curro Jiménez, y en aquellas otras que intentaban permeabilizar entre nosotros el diálogo como forma de resolver los conflictos, como en tantas ocasiones nos enseñan en "Verano azul", encontraron en Andalucía el caldo de cultivo y el espacio simbólico más adecuado para los nuevos valores.

La televisión, que progresivamente desplazó al cine como medio prioritario de entretenimiento masivo, encontró uno de sus mejores aliados en los clichés que tan bien habían funcionado durante décadas como instrumentos para la captación de audiencias en el cine español. Por otra parte, los formatos de entretenimiento televisivos se han convertido en cauces preferentes para la creación y difusión de estereotipos, entre otras razones, debido a que estas figuras resultan muy fácilmente reconocibles por el espectador $\mathrm{y}$, por lo tanto, propician que éste las identifique rápidamente. Así resulta más sencillo crear lazos de empatía entre las audiencias y los contenidos de los medios. Además, debemos tener en cuenta que este tipo de programas resulta particularmente eficaz como vehículo transmisor de valores sociales puesto que, al estar asociado con la evasión, la carga cultural que lleva implícita es menos evidente para los receptores.

Partiendo de estas premisas, el objeto del presente trabajo consiste en analizar de manera exhaustiva los tópicos relacionados con Andalucía que continúan vigentes a través de los diferentes formatos de entretenimiento en televisión.

\section{LOS ÁLVAREZ QUINTERO Y LOS CADAVAL, PRIMOS HERMANOS}

Para evitar que este enunciado dé pie a confusiones, empezaremos aclarando que no existe ningún tipo de parentesco por consanguinidad entre las citadas parejas de creadores sevillanos. Los definimos como primos hermanos atendiendo a la acepción figurada de esta expresión que habitualmente se emplea para reiterar la similitud entre dos elementos. Así pues, la licencia retórica sirve para condensar a la perfección la idea central de este primer apartado: la pervivencia de elementos cómicos y costumbristas en la representación de Andalucía. Estos recursos, empleados profusamente por los dramaturgos Serafín y Joaquín Álvarez Quintero en sus piezas teatrales entre finales del siglo XIX y las primeras décadas del XX, también fueron adoptados por el cine español desde los comienzos $y$, muchos años después, han sido reciclados y trillados en numerosos espacios televisivos. Por su relevancia, cuantitativa y cualitativa, la producción humorística de Los Morancos de Triana, el dúo integrado por Jorge y César Cadaval, se revela como una muestra paradigmática para estudiar la influencia de los modos de representación de antaño en los formatos de entretenimiento más recientes.

A comienzos del siglo XX, el teatro de los Álvarez Quintero resultó primordial en la construcción y difusión de una imagen típica de lo andaluz encorsetada entre la superficialidad y el extremismo. Además, los textos teatrales de estos autores 
constituyeron la base de alguna de las adaptaciones cinematográficas de ambientación andaluza que tuvieron un mayor éxito en los años treinta y cuarenta del siglo pasado. Sirvan como ejemplo las películas "La reina mora" (Eusebio Fernández Ardavín, 1936), "El genio alegre" (Fernando Delgado, 1939) "Malvaloca" (Luis Marquina, 1942) y "Mariquilla Terremoto" (Benito Perojo, 1949).

Entre los más de doscientos títulos que escribieron los dramaturgos sevillanos, pueden contarse comedias, dramas y zarzuelas pero, sin duda, fue el sainete el género que les hizo merecedores del favor del gran público.

El sainete es una respuesta creativa e histórica a una demanda de costumbrismo y comicidad, que a lo largo del tiempo ha sido satisfecha de diferentes formas. Y esa demanda continúa más allá de la imposible pervivencia de un género que ha acabado diluyéndose en otros ámbitos teatrales, cinematográficos, ${ }^{5}$ radiofónicos y ahora televisivos. Pero lo que en los mismos percibimos ya no es el sainete, sino lo sainetesco. Ya no cabe hablar de un género identificable como tal, sino de la presencia de alguno de sus elementos básicos en nuevas fórmulas que, en la mayoría de los casos, son el resultado de combinaciones de materiales y géneros de diversa procedencia. (Ríos, 1998).

Por su parte, Los Morancos de Triana también han conseguido atraer y fidelizar poderosamente a la audiencia española durante años. El secreto de su permanencia en la pequeña pantalla tiene mucho que ver con la influencia sainetesca descrita por Ríos. A grandes rasgos, cabe afirmar que estos humoristas trianeros se sirven de fórmulas narrativas en las que los recursos cómicos se entremezclan con referentes populares y argumentos cotidianos, habitualmente salpicados de elementos folclóricos.

Desde que iniciaron su carrera televisiva en la gala de TVE-1 "Viva el 85", los hermanos Cadaval han actuado en numerosos programas e incluso han dispuesto de los suyos propios. De todos ellos, destacamos "Entre morancos y omaítas" (TVE-1, 1997-1998) por el profundo calado de sus sketchs corales con personajes andaluces de extracción popular, como Omaíta, Antonia, Paco y Chariní. La ambientación costumbrista de los decorados, las marcadas estridencias en el vestuario, la deformación de los rasgos dialectales de los protagonistas y la ridiculización de su incultura son algunos de los ingredientes más suculentos de esta representación tópica y peyorativa de Andalucía.

Omaíta y compañía se han prodigado posteriormente en otros espacios, como "Omaíta en la Primera" (2001) y "El retorno de Omaíta" (2003), ambas emitidas en TVE-1. Por su parte, "Moranquíssimo" (televisiones autonómicas, ${ }^{7}$ 2004) supuso

\footnotetext{
${ }^{5}$ La presencia de lo sainetesco en el medio cinematográfico también ha sido abordada extensamente en la obra de Juan Antonio Ríos Carratalá (1997).

${ }^{6}$ Con excepciones como la de Charini, en general, los personajes principales de los sketchs de Los Morancos de Triana están interpretados por ellos mismos. Se trata de un formato articulado en torno a la omnipresencia del dúo de humoristas-imitadores (recordemos otros casos similares, como el de Martes y Trece y el de Cruz y Raya).

${ }^{7}$ Canal Sur Televisión, Televisión de Castilla-La Mancha y Televisión Canaria.
} 
la consolidación de personajes como la vidente Rosita de Jericó y los manteros sudamericanos Wilson y Linda. Estos últimos eran los encargados de presentar el particular top-manta de la semana, en el que se parodiaban las canciones más exitosas del momento y algunos clásicos, abordando de este modo una amplia gama de títulos nacionales e internacionales. Así se diluyeron parcialmente las continuas referencias explícitas a Andalucía en los programas de Los Morancos de Triana, a pesar de que los recursos formales utilizados en la puesta en escena no hubiesen variado sustancialmente. De todos modos, los tópicos folclóricos continuaron presidiendo numerosas actuaciones musicales, los guiones de las entrevistas y la mayor parte de los sketchs.

Actualmente, los particulares “Álvarez Quintero de la era del espectáculo” participan como miembros del jurado en el talent-show "Tú sí que vales" (Telecinco, 2008- ). Una de las principales fuentes de conflicto que se barajan en este espacio televisivo es la contraposición estereotipada en clave de humor de andaluces y catalanes, que están representados, respectivamente, por Los Morancos y el polifacético showman barcelonés Ángel Llàcer.

En general, la nutrida cantera de humoristas andaluces ha constituido siempre un poderoso reclamo para el gran público de los formatos de entretenimiento televisivos. Una buena muestra de ello es el éxito obtenido por artistas como Pepe da Rosa, Chiquito de la Calzada o el Dúo Sacapuntas, cuyos integrantes alcanzaron la popularidad con la ayuda de un cliché hiperbólico y despectivo de los habitantes de Lepe (Huelva). Sin olvidar a los jóvenes, como Manu Sánchez, que se ha convertido en uno de los comunicadores más recurrentes de Canal Sur Televisión en su etapa actual. Asimismo, entre las profesionales del humor, despunta la gaditana Paz Padilla por ser la que más ha contribuido a que siga vigente en el imaginario colectivo la figura de la andaluza resuelta que anteriormente fue difundida a través del teatro y del medio cinematográfico ${ }^{8}$.

\section{PASIÓN, MUERTE Y RESURRECCIÓN DEL STAR SYSTEM FOLCLÓRICO}

En España, especialmente a partir de los años treinta, empezaron a emplearse en el cine una serie de fórmulas estandarizadas para buscar el éxito comercial. Entre estas estrategias, destaca como elemento decisivo la consolidación del star system que dio vida a una serie de personajes cuyos rasgos característicos fueron unificados atendiendo a los gustos y valores vigentes en la época.

Entre las estrellas que triunfaron en el género folclórico, las actrices fueron mucho más conocidas y apreciadas por el público que los actores, salvo excepciones como las de Luis Mariano y Antonio Molina a partir de la década de los cincuenta. Así pues, intérpretes como Imperio Argentina, Estrellita Castro, Juanita

\footnotetext{
"Tras su etapa al frente de "Paz en la tierra" (2008-2009), un late night de Canal Sur Televisión, Paz Padilla se ha encargado de presentar en las tardes de los viernes el magacín "Sálvame Diario" (2009-), uno de los más notables éxitos de audiencia de Telecinco en los últimos tiempos.
} 
Las secuelas de los tópicos folclóricos del cine español. Un diagnóstico de los formatos de entretenimiento televisivos

Reina, Lola Flores y Carmen Sevilla se convirtieron en auténticos símbolos ${ }^{9}$. Las películas en las que aparecían y el reflejo que se daba de ellas en los medios de comunicación sirvieron para configurar todos los atributos que ayudaron a transformar a estas estrellas en emblemas sociales.

Además, la intención de las productoras era que estos mitos se pusieran al alcance de la mayoría de los espectadores para que quienes acudían a las salas de cine pudieran llegar a pensar que era posible convertirse en su estrella favorita. De este modo, las actrices aportaban entidad a las películas y, en correspondencia, iban manteniendo o aumentando su posición como miembros del star system en función de las cifras de taquilla alcanzadas por las obras que interpretaban.

La figura de las estrellas se diseñaba "con un perfil característico para extenderse por una serie de películas de acuerdo con las exigencias del público" (Sánchez-Biosca y Benet, 1994: 9). En definitiva, los rasgos externos de los personajes que encarnaban las folclóricas, como la expresión inmoderada de los sentimientos o el bajo nivel cultural asociado al habla andaluza, se integraban también en la configuración de su imagen pública para contribuir a su acercamiento a las clases populares.

Sin embargo, estos atributos diferenciales que hasta entonces habían identificado lo andaluz resultaron poco acordes con la imagen de modernidad que pretendía ofrecer el cine en la década de los sesenta. El género folclórico comenzó a declinar al tiempo que Marisol, rubia, de ojos azules y rasgos dialectales suavizados, se imponía en la gran pantalla como el nuevo modelo de andaluza. A pesar de apuestas tan fuertes como "El balcón de la luna" (Luis Saslavsky, 1962), protagonizada por Lola Flores, Carmen Sevilla y Paquita Rico, las folclóricas de siempre nunca volvieron a recuperar su estatus en el medio cinematográfico. Pero a muchas les supo a poco quedar para actuar en los teatros y en los espacios musicales de la televisión, poner rostro a unos cuantos productos novedosos en los inicios de la sociedad de consumo y prodigarse en las revistas del corazón.

Sin duda, el medio televisivo ha contribuido a rescatar, años después, a algunas de estas grandes folclóricas que ha dado el cine español. Quedan en la memoria espacios como "El tablao de Lola" (Telecinco, 1992), presentado por Lola Flores, o la serie "El coraje de vivir" (Antena 3, 1994), en la que la cantante y bailaora jerezana hablaba de su vida privada con todo lujo de detalles. Asimismo, junto a su hija Lolita, fue la encargada de conducir "Sabor a Lolas" (Antena 3, 1992-1993) y "Ay, Lola, Lolita, Lola" (TVE-1, 1995). En suma, el interés del público por la Faraona, incluso tras su muerte, ha contribuido a impulsar numerosas producciones de diversa índole en torno a esta mítica figura. Cabe destacar la implicación de Antena 3 en una de las iniciativas más ambiciosas al respecto,

\footnotetext{
'Un estudio pormenorizado de la representación cinematográfica de la figura femenina andaluza puede encontrarse en RUIZ y SÁNCHEZ (2008).
} 
“Lola, la película" (Miguel Hermoso, 2007) ${ }^{10}$, una obra en la que se aborda la trayectoria de la artista, haciendo especial hincapié en los detalles de su relación íntima con Manolo Caracol.

Resulta igualmente significativo que Telecinco se arriesgase en el comienzo de su andadura con Carmen Sevilla como presentadora del espacio "Telecupón" (1990-1998). Si en sus apariciones televisivas Lola Flores encarnaba a la misma andaluza rebelde y pasional a la que dio vida en la mayor parte de su filmografía durante la etapa franquista, Carmen Sevilla explotaba los típicos rasgos de la bella inocente con la que alcanzó la fama. Aunque, tanto años después, como es natural, el personaje resultaba decadente y acartonado, lo cual sirvió para incentivar el cariño y la simpatía de los espectadores. Desde entonces, esta folclórica sevillana ha continuado presentando programas en diferentes cadenas, difundiendo así la imagen de una mujer andaluza inculta e histriónica, características éstas que aparecen compensadas por una desmedida simpatía. En los últimos años, Carmen Sevilla ha conducido el espacio "Cine de barrio" de TVE-1 (2003- ), dedicado a rememorar los clásicos del cine popular español.

Además de las folclóricas de siempre, han sido muchos los personajes mediáticos que han contribuido a mantener viva la representación estereotipada de las tradiciones asociadas a Andalucía y a lo andaluz, como los toros, las festividades religiosas o las reuniones en las tabernas. Tampoco es casualidad que hayan sido andaluzas algunas de las indiscutibles reinas del papel cuché, como la mencionada Lola Flores, Carmen Ordóñez, Rocío Jurado e Isabel Pantoja, cuyas historias familiares se han convertido prácticamente en telenovelas en vivo a través de los espacios televisivos de crónica social.

Que los tiempos han cambiado en el panorama musical es indiscutible, y una buena muestra de ello es que reconocidas intérpretes de copla de la nueva hornada, como Pasión Vega o Pastora Soler, alternen con naturalidad los vestidos de volantes con juveniles trajes de noche o la copla clásica con ritmos más actuales, como las baladas o el pop ${ }^{11}$. No obstante, incluso estas artistas han apoyado con su presencia el intento más reciente de resucitar la copla tradicional en todas sus dimensiones: "Se llama copla" (Canal Sur Televisión, 2007- ).

En este reality-show musical, se ha apostado fuertemente por ensalzar las canciones más emblemáticas del ayer y por la profusión de elementos tópicos

\footnotetext{
${ }^{10}$ Otra gran apuesta de Antena 3 en una línea similar ha sido la miniserie "Marisol", dirigida por el cineasta Manuel Palacios, que fue emitida en marzo de 2009.

${ }^{11}$ Ciertamente, también pueden contarse otras cantantes veteranas cuyos aportes en la transformación de los tópicos andaluces en el terreno musical han resultado muy significativos. Por ejemplo, la onubense Martirio (cuyo primer disco en el mercado, "Estoy mala", data de 1986) fue una de las primeras en fusionar la copla española con el pop-rock y en aportar a los géneros populares matices hiperrealistas a través de sus letras. El personaje que creó Maribel Quiñones también se caracterizó por una puesta en escena innovadora, de la que cabe destacar los fastuosos trajes que combinaban lo folclórico y lo posmoderno, las grandes peinetas de inspiración vanguardista y unas vistosas gafas oscuras de las que no se ha desprendido hasta el día de hoy.
} 
en la caracterización de los concursantes, quizá para hacerlos más fácilmente reconocibles por el público y contribuir así a que la nostalgia de los años dorados del género folclórico quedase bien sembrada en el prime time de los sábados ya desde el principio. Por otra parte, como en el cine de tiempos pasados, las productoras (Europroducciones y Caligari Films) se decantaron por enaltecer la figura femenina e introdujeron más mujeres que hombres entre los participantes, algo nada habitual hasta entonces en este tipo de programas.

"Se llama copla" consiguió la mejor cuota de pantalla de la historia de la televisión autonómica andaluza en su primera edición ${ }^{12}$. Después llegaron el cartel de agotadas todas las entradas en la Gira Presentación, la sucesión de conciertos de los participantes y un nuevo espacio televisivo que se nutría del entusiasmo que el programa había despertado en los espectadores andaluces:

\begin{abstract}
"Azúcar, canela y clavo" llega a la televisión pública andaluza con un claro objetivo, resaltar el papel de la copla y analizar la aportación cultural y social de este género musical a nuestra tierra. Aprovechando el gran éxito del programa "Se llama copla", ${ }^{13}$ espacio que ha dejado bien claro que la Copla está muy vigente en la actualidad, "Azúcar, canela y clavo" recupera aquellos temas o personajes míticos de este género, las grandes voces de la copla o la relación existente entre copla y toros ("Azúcar, canela y clavo", 2009).

El respaldo del público ha sido crucial para el desarrollo de dos ediciones posteriores de "Se llama copla". Además, Europroducciones TV ha aprovechado el eco de este concurso musical para poner en marcha una versión idéntica al formato original, "A tu vera" (2009), que se ha emitido en Castilla-La Mancha Televisión y 7 Región de Murcia con notables resultados de audiencia.
\end{abstract}

\title{
4. CASTING ABIERTO: VIEJOS ESTEREOTIPOS PARA NUEVOS FORMATOS
}

La novedad del Casting abierto posibilita que, al final de cada gala, un nuevo aspirante a estrella tenga la oportunidad de incorporarse al elenco de artistas, superando el Gran Reto: tendrá que elegir a uno de los concursantes menos votados de la noche y enfrentarse a él en un emocionante duelo musical. Si consigue superar la actuación del veterano y convence al jurado, habrá ganado su plaza en el programa (Europroducciones, 2009).

\footnotetext{
${ }^{12}$ En la Gala Final, celebrada el 23 de febrero de 2008, "Se llama copla" obtuvo una media del 52,7\% de share, alcanzando picos del $70 \%$ y casi del $80 \%$ durante las actuaciones de los concursantes. Fuente: http://www.formulatv.com/1,20080225,6915,1.html

13"Azúcar, canela y clavo" (2008) ha tenido como base material audiovisual de archivo de actuaciones de artistas consagrados y, con frecuencia, se ha alimentado también de las interpretaciones de temas clásicos realizadas por los concursantes de "Se llama copla". Además, tanto la conductora de "Azúcar, canela y clavo", Gema Carrasco, como los colaboradores de este espacio, el productor Pive Amador y el periodista Hilario López Millán, formaban ya parte del reality-show folclórico, como participante y miembros del jurado, respectivamente.
} 
El Casting abierto, empleado en "Se llama copla" y otros espacios ${ }^{14}$, es una fórmula sintomática del elevado número de concursantes potenciales que están dispuestos a mostrar sus aptitudes y habilidades ante las cámaras. El incremento de cadenas privadas nacionales en España a partir de 2005 (Cuatro, La Sexta), la dinamización en el sector de la producción audiovisual y la estandarización de los procesos de elaboración de nuevos formatos han sido algunos de los factores que han influido en la proliferación de convocatorias para procesos de selección televisivos de muy diversa índole.

El ciudadano no sólo alimenta a esta industria consumiendo estos programas desde casa, sino que además ahora se encarga de elaborarlos de manera prácticamente gratuita. [...] Los concursantes en espacios como "Gran Hermano" y "Operación Triunfo" obtienen cierta remuneración y la esperanza de extraer una rentabilidad futura, aunque los beneficios inmediatos que logran los empresarios son en comparación absolutamente desproporcionados. Algo similar ocurre en los programas del corazón, donde los famosos que acuden son remunerados sabiéndose partícipes de una industria que deben sustentar si quieren seguir alimentándose de ella. Pero frente a estas "explotaciones consentidas con fines lucrativos", la mayoría de los invitados anónimos a realities y talkshows no cobran nada a cambio de su participación (Tucho, 2005: 22).

Fernando Tucho, en su afán de profundizar en los mecanismos que rigen los que él ha denominado "géneros del máximo beneficio al mínimo coste", hilvana la relación de esta creciente participación altruista de los ciudadanos con "el poder que ejerce el mundo televisivo sobre un amplio sector de la audiencia, un público que tiene en la pequeña pantalla el centro de su relación con la esfera pública, y también su única vía de participación en la misma" (Tucho, 2005: 23). En el caso particular de los andaluces candidatos a exhibir sus virtudes o a compartir sus historias de vida en televisión, también debemos plantearnos en qué medida intentan explotar los clichés más tradicionales para caer en gracia a los directores de casting y al público que determina con su voto quiénes son los ganadores ${ }^{15}$. Actitudes como las de Conchi y Pamela, las gemelas de "Gran Hermano 9" (Telecinco, 2007), contribuyen a que nos planteemos seriamente esta hipótesis ${ }^{16}$.

En general, se observa que los tópicos andaluces han ido desplazándose a los formatos de telerrealidad, de manera progresiva, desde que comenzaron a implantarse a comienzos de la década actual. Laura Teruel y Florencio Cabello (2005) han llamado la atención sobre la elevada presencia de andaluces que hay en este tipo de programas, teniendo en cuenta que en ellos los participantes se

\footnotetext{
${ }^{14}$ Esta estrategia también ha sido la elegida para otros reality-shows musicales como "Hijos del Babel" (TVE-1/ La 2, 2008) y "Fama, ja bailar!" (Cuatro, 2008- ).

${ }^{15} \mathrm{No}$ se trataría, ni mucho menos, de una estrategia novedosa y reciente. Entre sus antecedentes, por ejemplo, podemos contemplar las consideraciones que establece Jo Labanyi (2003: 9-10) acerca de la rentabilidad de la apropiación del estereotipo gitano para la cultura andaluza en el siglo XIX.

${ }^{16}$ Reparamos también en que Mercedes Milá, al comienzo de esta edición del reality-show, apuntó que la organización había optado por incluir concursantes de las comunidades autónomas donde el programa alcanzaba mayores índices de audiencia, entre las que se encontraba Andalucía.
} 
Las secuelas de los tópicos folclóricos del cine español. Un diagnóstico de los formatos de entretenimiento televisivos

escogen por su perfil: las selecciones de individuos procedentes de Andalucía están habitualmente encaminadas a encontrar personas extrovertidas y con sentido del humor.

Consideremos, además, las conclusiones de estos autores acerca de la inclusión de concursantes de esta comunidad en "Operación Triunfo" (TVE-1, 20012004; Telecinco, 2005-2009):

Los productores encuentran en el estereotipo andaluz personajes propicios para construir la imagen del programa dedicada al cante y al baile porque sugieren, para los espectadores, valores ya conocidos. Se ejercita un acto de economía intelectual: los productores ofrecen a los espectadores un producto sobre el que tienen una idea formada que encaja con lo que se pretende emitir. [...] Se benefician de la imagen estereotipada del andaluz artista y alegre como carta de presentación para la audiencia (Cabello y Teruel, 2005).

Estos mecanismos son los que, por ejemplo, facilitaron que Rosa López se convirtiera en Rosa de España de la noche a la mañana y, por ende, en uno de los mejores productos mediáticos de los últimos años. Puede hacerse una idéntica lectura de la habitual inclusión en "¡Mira quién baila!” (TVE-1, 2005-2009) de carismáticos famosos andaluces, como el torero Martín Pareja Obregón, las folclóricas María del Monte y Carmen Sevilla o el humorista Manolo Sarriá. Asimismo, tampoco se debe al azar el arte y la gracia de los pequeños colaboradores de "Menuda noche" (Canal Sur Televisión, 2003- ), de cuya cantera han salido las precoces cantantes María Figueroa y María Carrasco.

$Y$ es que los elementos tradicionalmente empleados para representar a Andalucía tienen mucho peso. En el extremo, encontramos muestras como "El cortijo de 1907" (Canal Sur Televisión, 2007), un docu-reality en el que dos familias andaluzas convivieron durante más de dos meses en una finca rústica equipada únicamente con utensilios domésticos similares a los de comienzos de siglo ${ }^{17}$. Con este espacio, la cadena de televisión autonómica se convirtió en líder del prime time de los domingos.

\section{LAS REELABORACIONES TELEVISIVAS DE LOS TÓPICOS ANDALUCES}

Con el paso del tiempo, hasta los estereotipos más arraigados se van transformando de manera más acorde con la estética y los valores vigentes. Por citar un ejemplo, en el programa "Bienaventurados" (Canal Sur Televisión, 2006-2007) se generó un espacio insólito para la convivencia entre los elementos folclóricos tradicionales y algunas de sus reelaboraciones más extravagantes. Este tono quedó subrayado a través de la escenografía, del vestuario y de la caracterización

\footnotetext{
${ }^{17}$ Incluso en programas con una mayor vocación pedagógica, como "Andaluces por el mundo" (Canal Sur 2, 2006- ), la nostalgia suele metamorfosearse en guitarra flamenca, carreta de El Rocío o patio cordobés, en definitiva, elementos que el espectador pueda asociar fácilmente a la iconografía andaluza.
} 
estética y psicológica de los personajes habituales, incluida la propia presentadora, la cantante María Jiménez.

María del Monte, por su parte, ha sido una de las estrellas musicales más solicitada durante los últimos años para conducir programas dedicados a la copla, por su implicación con el género y, seguramente, por su imagen de andaluza resuelta, muy acorde con este tipo de formatos. Sin embargo, nos sorprendió en su magacín "La tarde con María" (Canal Sur, 2007-2009) con una sección denominada "Taichi coplero", en la que se enseñaba a practicar relajación y meditación al compás de clásicos de la canción española que habían sido adaptados a los ritmos más modernos. De todos modos, en este programa prevalecía un marcado tono costumbrista, apoyado fuertemente en el ensalzamiento de los valores más tradicionales.

Si se trata de estudiar la vigencia de lo sainetesco en el medio televisivo, no podemos pasar por alto las series de ficción nacionales debido a su valor testimonial. Además, por sus características formales y de contenido, han resultado especialmente idóneas para vehicular el proceso del desplazamiento de los tópicos andaluces del cine a la televisión, especialmente en lo que se refiere a los mecanismos de construcción de personajes.

En este sentido, uno de los casos más ejemplificadores ha sido el de Juani (Luisa Martín), la empleada de hogar andaluza de "Médico de familia" (Telecinco, 1995-1999). Detrás de ella vinieron otras sureñas con rasgos que remitían inequívocamente a los estereotipos cinematográficos de antaño, como Laura ( $\mathrm{Paz}$ Vega) en "Siete vidas" (Telecinco, 1999-2006 ${ }^{18}$ ), Manuela (Aurora Sánchez) en "Ana y los siete" (TVE-1, 2002-2005) y Carmen (Rosario Pardo) en "Con dos tacones" (TVE-1, 2006). Teniendo en cuenta que los tópicos andaluces que años atrás colmaron la gran pantalla fueron asociados de manera preferente al género femenino, no debe extrañarnos que los personajes televisivos andaluces de mayor trascendencia también hayan sido mujeres mayoritariamente.

La gracia, la incultura, la expresión inmoderada de los sentimientos, la buena fe y el apego a la tradición continúan siendo los rasgos más utilizados para dibujar a las mujeres de Andalucía. Hasta el punto que muchos espectadores aún tienen la creencia errónea de que Choni, la hermana de Fiti en "Los Serrano" (Telecinco, 2003-2008 ${ }^{19}$ ), era oriunda de esta región. El marcado acento murciano (parecido al andaluz) de Pepa Aniorte, la actriz que encarna a Choni, ha resultado insuficiente para dejar clara su auténtica procedencia ${ }^{20}$. La confusión se debe, en gran parte, a que la estereotipada caracterización interna y externa de Choni era idéntica a la que habitualmente se les ha atribuido a las mujeres andaluzas.

\footnotetext{
${ }^{18}$ Aunque la serie finalizó en 2006, la actriz Paz Vega únicamente intervino en las dos primeras temporadas (1999-2000).

${ }^{19} \mathrm{El}$ personaje de Choni (2006-2008) se incorporó en la quinta temporada.

${ }^{20} \mathrm{En}$ diversos capítulos de la serie, se ha hecho referencia explícita al origen murciano del personaje de Choni.
} 
Merece especial consideración la figura de Macu (Pepa Rus) en "Aída" (Telecinco, 2005-200921). Frente a las andaluzas que protagonizan las tramas costumbristas de los géneros más tradicionales, la sobrina de Mauricio Colmenero supone la elevación a la máxima potencia del arquetipo andaluz. Para comprender la hiperbolización de los atributos del personaje, no podemos olvidar que esta serie debe analizarse teniendo presentes los parámetros narrativos que rigen la sit-com. Aún así, los elementos definitorios de Macu presentan matices extremadamente peyorativos. En definitiva, los modos de representación que aquí se emplean no resultan sainetescos sino grotescos ${ }^{22}$. También deja mucho que desear el histrionismo característico de Richard de Castro (David Arnáiz) y de Puri (Sofía Monreal) en la telenovela cómica "Yo soy bea" (Telecinco, 2006-2009).

Sin duda, en las series españolas, continúa arraigada una estrecha vinculación entre lo andaluz y la comedia. A los ejemplos ya apuntados, cabría añadir otros casos destacados como el de "Los hombres de Paco" (Antena 3, 2005-2009). Se trata de la primera ficción televisiva que se ha realizado en torno al Cuerpo Nacional de Policía en clave de humor negro. Tanto el Inspector Paco Miranda (Paco Tous) como uno de sus dos hombres de confianza, Mariano (Pepón Nieto), son oriundos de Andalucía y mantienen los rasgos dialectales propios de la región. Son los dos agentes toscos, torpes, bonachones y salerosos, los que protagonizan las tramas más rocambolescas. Sin embargo, Lucas (Hugo Silva), el policía apuesto y atrevido, es madrileño y el recto Comisario Don Lorenzo también se expresa como tal, a pesar de estar interpretado por el sevillano Juan Diego. En lo que respecta a los personajes femeninos andaluces, tanto Rita (Neus Sanz) como Pepa Miranda (Laura Sánchez)23 a pesar de ser moderna y audaz, se caracterizan en gran medida por su efusividad, su sentido del humor y ciertas trazas costumbristas.

Finalmente, nos centraremos en los culebrones del canal autonómico de Andalucía, "Plaza Alta" (1998-2000) y "Arrayán" (2001- ), en los que se observa una considerable evolución. A pesar de la frecuente inclusión de personajes y tramas costumbristas en ambas telenovelas, ha supuesto un paso adelante que "Arrayán" transcurra en un hotel de nuestra comunidad mientras que "Plaza Alta" se desarrollaba en el ámbito rural. Con esta última afirmación, únicamente pretendemos subrayar la importancia de que los productores y los emisores se decantasen por elegir, en la segunda ocasión, un marco espacial más acorde con el clima de desarrollo de la Andalucía actual ${ }^{24}$.

\footnotetext{
${ }^{21}$ Macu apareció por primera vez en la cuarta temporada (2007).

${ }^{22}$ Los mismos conceptos, aunque en menor medida, determinan la concepción de los personajes de la sit-com "S.O.S. Estudiantes" (Canal Sur 2, 2003-2007).

${ }^{23}$ El personaje de Pepa Miranda se agregó en la cuarta temporada (2008).

${ }^{24}$ De "Arrayán" surgió el spin off semanal "Rocío, casi madre" (Canal Sur Televisión, 2007-2008). La historia transcurre en Alminares, un pequeño pueblo andaluz donde constantemente se confrontan los personajes anclados en la tradición con otros cuya mentalidad sí ha evolucionado. Tal vez esta bipolaridad sea una de las claves que explique el éxito de público de esta serie y de otras basadas en planteamientos similares, como "Padre Medina" (Canal Sur Televisión, 2009- ).
} 


\section{APUNTES PARA LA REFLEXIÓN}

El medio televisivo ha contribuido poderosamente a que los clichés tradicionalmente asociados a Andalucía continúen vigentes en la sociedad española. Asimismo, queda patente la necesidad de que, desde la pequeña pantalla, se ofrezca una visión más matizada y, por ende, más moderna y real, tanto de nuestra región como de sus habitantes. ¿Pero cuál es la participación de los propios andaluces en todo este proceso?

Probablemente sin los medios no habría estereotipos. Es verdad que se han convertido en el mejor instrumento social para la transmisión de fábulas, de conocimientos, de tópicos y pautas de comportamiento, pero también es verdad que despreciamos todas estas formas como veneno cuando no nos complacen. Los estereotipos positivos (simpatía, hospitalidad, buen carácter...) no encuentran trabas para su promoción. [...] Mientras tanto, aquellos otros que puedan hacernos daño se filtran y desmenuzan, tratándolos como una ofensa (González, 1999: 105).

¿Por qué "Moranquíssimo", "Se llama copla" y "Aída" se cuentan entre los programas más vistos en la comunidad andaluza?

\section{REFERENCIAS BIBLIOGRÁFICAS}

AZÚCAR, CANELA Y CLAVO: [En línea]. [Consulta: 10 octubre 2009]

$<$ http://www.canalsur.es/web/programa?pag=/contenidos/programas/azucar canela_y clavo/descripcion_programa\&programa $=a z u c a r \_c a n e l a \_y \_c l a v o \& i d D r c=65208 \&$ idActivo $=6520$ 8\&idCanal $=63 \& \mathrm{vE}=\mathrm{C} 62, \mathrm{C} 66>$

COMAS, A. (2004): El star system del cine español de posguerra, 1939-1945. Madrid: T\&B Ediciones.

EUROPRODUCCIONES: [En línea]. [Consulta: 10 octubre 2009]

$<$ http://www.europroducciones.com/television/verPrograma.asp?id=144>

GONZÁLEZ, R.: "La construcción de estereotipos andaluces por los medios", Comunicar, n० 12 (1999), pp.101-106.

LABANYI, J. (2003): Lo andaluz en el cine del franquismo: los estereotipos como estrategia para manejar la contradicción. Sevilla: Fundación Centro de Estudios Andaluces.

PALACIO ARRANZ, M.: Notas para una comprensión sinóptica de la televisión en la Transición democrática. Área abierta, n 3 [en línea]. 2002 [Consulta: 10 octubre 2009] <http://revistas.ucm.es/inf/15788393/articulos/ARAB0202230004A.PDF>

Ríos CARRATALÁ, J. A. (2006): El teatro de Carlos Arniches y los hermanos Álvarez Quintero. Alicante: Biblioteca Virtual Miguel de Cervantes. [En línea]. [Consulta: 10 octubre 2009]

< http://descargas.cervantesvirtual.com/servlet/sirveObras/01361620811248417868024/020042.pdf?incr=1> 
- El sainete y lo sainetesco: una propuesta. En CANTOS CASENAVE, M. E.; y ROMERO FERRER, A. (coords.) (1998): Pedro Muñoz Seca y el teatro de humor contemporáneo (1898-1936). Il Congreso de Historia y Crítica del Teatro de Comedias, El Puerto de Santa María (Cádiz), Agosto 1996. Cádiz: Universidad de Cádiz. Servicio de Publicaciones.

- (1997): Lo sainetesco en el cine español. Alicante: Universidad de Alicante.

RUIZ MUÑOZ, M. J.: "Argumentos, personajes y escenarios para la reelaboración de la imagen de Andalucía en el cine (1975-2006)", Palabra Clave, no 11 (2008), pp.123-139.

RUIZ MUÑOZ, M. J.; y SÁNCHEZ ALARCÓN, I. (2008): La imagen de la mujer andaluza en el cine español. Sevilla: Fundación Centro de Estudios Andaluces.

SÁNCHEZ ALARCÓN, I. (coord.); RUIZ MUÑOZ, M. J.; y TERUEL RODRÍGUEZ, L.: LoS valores del régimen franquista a través del reflejo de la mujer andaluza en el cine español. En GARCÍA-BAQUERO GONZÁLEZ, A. (2002): Actas del III Congreso de Historia de Andalucía, tomo II (La mujer). Córdoba: Publicaciones Obra Social y Cultural Cajasur, pp. 431-448.

SÁNCHEZ- BIOSCA, V.; y BENET, V. J.: "Las estrellas: un mito en la era de la razón", Archivos de la Filmoteca, no 18 (1994), pp. 5-10.

SE LLAMA COPLA: [En línea]. [Consulta: 10 octubre 2009]

$<$ http://sellamacopla.canalsur.es>

TERUEL RODRÍGUEZ, L.; y CABELLO FERNÁNDEZ-DELGADO, F.: "Andaluces en la telerrealidad: la audiencia a través del estereotipo del andaluz anónimo en televisión", Comunicar, n 25 (2005) (CD-ROM).

TRENZADO ROMERO, M.: "La construcción de la identidad andaluza y la cultura de masas: el caso del cine andaluz", Revista de Estudios Regionales, $\mathrm{n}^{\circ} 58$ (2000), pp. 185-207.

TUCHO, F.: "Realities, talk-shows y programas del corazón: un análisis desde sus condiciones de producción", Pueblos, n 16 (2005), pp. 21-23.

\section{Breve semblanza biográfica de la autora}

María Jesús Ruiz Muñoz es Profesora de Comunicación Audiovisual y Publicidad (UMA). Su línea de investigación gira en torno al estudio de la representación de identidades culturales en los medios audiovisuales. Integrante del grupo que desarrolla el proyecto del Plan Nacional de I+D+i "Instrumentos y mediciones de análisis de la ficción en la convergencia televisiva" (CSO2009-12568-C03-01) y del grupo PAIDI HUM-664 sobre "Estudios sobre Comunicación y Sociedad de la Información".

(Recibido el 30-11-2009, aceptado el 01-04-2010) 